\title{
Endogenous Plant Hormone Profiles in Growing Melon Fruit
}

\author{
Kiyohide KOJIMA $^{1}$, Hayata NomURA ${ }^{2}$ and Daigo AnDOU $^{3}$ \\ ${ }^{1}$ Faculty of Agriculture, Niigata University, Ikarashi 2, Nishi-ku, Niigata 950-2181 \\ ${ }^{2}$ Graduate School of Science and Technology, Niigata University, Ikarashi 2, Nishi-ku, Niigata 950-2181 \\ ${ }^{3}$ Graduate School of Agriculture, Kyoto University, Kitasirakawa-oiwake Sakyo-ku, Kyoto 606-8502
}

(Received July 21, 2020; Accepted March 6, 2021)

\begin{abstract}
In this study, we explained the phytohormone profiles associated with various stages of melon fruit growth. This is achieved using melon fruits were obtained 14 to 56 days after flowering (DAF) and grouped into the rind, pulp, and placenta part (including seeds). The peduncle part (including the petiole of about $10 \mathrm{~cm}$ in length) was also obtained. Furthermore, using liquid chromatography-mass spectrometry (LC-MS), we quantified simultaneously indole-3-acetic acid (IAA), abscisic acid (ABA), trans zeatin (tZ), isopentenyladenine (iP), jasmonic acid (JA), methyl jasmonate (MeJA), gibberellin ${ }_{1}\left(\mathrm{GA}_{1}\right)$ and gibberellin ${ }_{4}\left(\mathrm{GA}_{4}\right)$ obtained from various tissues. $\mathrm{tZ}$ and $\mathrm{iP}$ concentrations increased at $42 \mathrm{DAF}$ in the placenta part but rapidly declined at $56 \mathrm{DAF}$. The $\mathrm{GA}_{4}$ concentration was similar in the placenta part, the rind, and flesh within the fruit, but changed differently in the peduncle part outside the fruit, rapidly increasing to $28 \mathrm{DAF}$ and continuing to decrease thereafter. ABA concentration in the placenta part continued to increase with the progress of fruit growth. In the rind, the concentrations of JA and MJA were generally high. In conclusion, our results revealed an endogenous plant hormone profile in grape fruit growth.
\end{abstract}

Keywords : ABA, cytokinin, GA, IAA, jasmonic acid, trans zeatin

\section{INTRODUCTION}

Melon is a crucial cultivar in the Cucurbitaceae family and is the third most-produced in the world (FAO, 1994). Thus, different phytochemical regulators have been examined to produce high-quality fruits, develop labor-saving and low-cost cultivation methods: promotion of fruit set by synthetic cytokinins, 6-benzylaminopurine (BA) (Jones, 1965), and acceleration of fruit set by 1- (2-Chloro4-pyridinyl) -3-phenylurea (CPPU) (Li et al., 2002); increase of sucrose concentration by synthetic auxin, $\mathrm{p}$ chlorophenoxyacetic acid (p-CPA) (Hayata et al., 2002). Additionally, the mechanism of this formation is not clear despite a unique net is generated in Earls melons.

Fruit growth is regulated by various plant hormones (Gillaspy et al. 1993). Therefore, analysis of the endogenous amounts of major plant hormones will lead to the elucidation of developmental physiology and the development of techniques for overcoming physiological disorders.

The following studies are known on the levels of endogenous hormones in melon fruits: analysis of indole-3acetic acid (IAA) at 5-35DAF (days after flowering) in seeds and pulp by high performance liquid chromatography (HPLC) with a fluorescence detector (Lee et al., 1997); analysis of abscisic acid (ABA) at 20-60 DAF seeds and pulp by enzyme linked immune sorbent assay (ELISA) (Welbaum et al., 2000); gas chromatographymass spectrometry (GC-MS) analysis of IAA and ABA for
10 days after treatment with synthetic cytokinin on flowering (Hayata et al., 2002). It has also reported that analysis of IAA, ABA and gibberellin (GA) in the rind, pulp and placenta of seeded and non-seeded grape cultivars by HPLC (Wang et al., 1993).

However, there is no report on the simultaneous analysis of major phytohormones of each tissue in growing melon fruit by the current reliable mass detector. Therefore, in this study, eight major endogenous hormones, IAA, ABA, trans-zeatin (tZ), isopentenyl adenine (iP), jasmonic acid (JA), methyl jasmonate (MeJA), and GA ( $\mathrm{GA}_{1}$, $\mathrm{GA}_{4}$ ) were concurrently quantified by instrumental analysis. This study is elucidate the phytohormone profiles at various stages during melon fruit growth.

\section{MATERIALS AND METHODS}

\section{Plant materials}

Seedlings of melon (Cucumis melo L. 'Ichibakouji') were produced by own roots and cultivated by a farmer near the Niigata University: soil cultivation in tunnels; four fruits per plant with two secondary vines; $55 \mathrm{~cm}$ between plants. On the day of flowering, it was artificially pollinated with male pollen. Twenty fruits were obtained at each of 14, 28, 42 and 56 days after flowering (DAF). Suzuki and Nonaka (2004) reported formation of a unique net in the rind of Earls melon. Melons have cracks between the cells of the rind around 19 DAF, and vertical direction cracks can be visually seen. Around 23 DAF, the horizon-

Corresponding author : Kiyohide Kojima, fax: +81-25-262-6612, e-mail : kojimaki@agr.niigata-u.ac.jp 


\section{K. KOJIMA ET AL.}

tal direction and fine cracks can be observed virtually. Around $30 \mathrm{DAF}$, the rind has nets throughout the fruit. After harvesting, 20 fruits were grouped into the rind, the flesh, and the placenta part (including seeds) with a knife. The peduncle part (also called the antenna, including the petiole of about $10 \mathrm{~cm}$ in length) that was left after adjustment when shipping the high-grade melon was also obtained. The pulp from 20 fruits were weighed together and then ground, and the soluble solids was measured with a digital refractometer using about $1 \mathrm{~g}$ of the ground liquid (RP-101, Atago, Tokyo, Japan). The remaining grinding liquid was immersed in $80 \%$ ethanol and stored at $-40^{\circ} \mathrm{C}$ until extraction. The rind, flesh, placenta part, and peduncle part were also together weighed and then immersed in $80 \%$ ethanol and stored at $-40^{\circ} \mathrm{C}$ until extraction.

Analysis for IAA, ABA and JAs

Hormone analysis was performed according to the procedure of Kojima et al. (2020). Briefly, the rind and seeds were homogenize and the three tissues were filtered into a stock solution of about $80 \%$ ethanol. We added ${ }^{13} \mathrm{C}_{6}$ IAA, $\mathrm{d}_{6}-\mathrm{ABA}, \mathrm{d}_{2}-\mathrm{JA}$, and $\mathrm{d}_{2}$-MeJA as internal standards to stock solution of about $80 \%$ ethanol (equivalent to $1 \mathrm{~g}$ fresh weight). We concentrated aqueous solution, adjusted $\mathrm{pH}$ to 2.8 and filtered. Partition extraction was performed with diethyl ether, which was concentrated and filtered.

The extracts were fractionated with HPLC (LC20AD, Shimadzu Co., Japan) system I equipped with an ultraviolet detector (Kojima et al., 2002). The HPLC column (Inertsil ODS-3, $3 \mu \mathrm{m}, 10 \times 250 \mathrm{~mm}$, GL Sciences Inc., Japan) was isocratically eluted with a solution of $40 \%$ ethanol. Eluates corresponding to the retention times of IAA, ABA, JA, and MeJA were collected separately. IAA and $\mathrm{ABA}$ fractions were dried under reduced pressure, and JA and MeJA fractions were concentrated under reduced pressure to approximately $1 \mathrm{~mL}$. After fractionation by HPLC system I, all fractions were further purified with the same type HPLC system II. HPLC column (C-30-SSelect) was isocratically eluted with a solution of $40 \%$ ethanol. Eluates corresponding to each retention time of IAA, ABA, JA, and MeJA were collected and concentrated.

Analysis for GAs and CKs

Hormone analysis was performed according to the procedure of Kojima et al. (2020a). We added $d_{5}-t Z, d_{6}$ iP, $\mathrm{d}_{2}-\mathrm{GA}_{1}$ and $\mathrm{d}_{2}-\mathrm{GA}_{4}$ as internal standards to stock solution of about $80 \%$ ethanol (equivalent to $9 \mathrm{~g}$ fresh weight). The concentrated solution was adjusted to $\mathrm{pH} 3.5$ and filtered. Partition extraction was performed using ethyl acetate (Kojima et al., 2003). The ethyl acetate layer: Anhydrous sodium sulfate was added to the ethyl acetate layer for dehydration and allowed to stand overnight. The ethyl acetate layer was decanted, concentrated and filtered. The aqueous layer: $\mathrm{pH}$ of the aqueous layer was adjusted to 7.0, partitioned, and extracted with butanol. The butanol layer was concentrated, dissolved in 50\% ethanol, and filtered.

Extracts from the ethyl acetate and butanol layers were fractionated using the HPLC system I. From the ethyl acetate layer, eluates corresponding to $\mathrm{GA}_{1}, \mathrm{GA}_{4}$, and iP were collected separately. From the butanol layer, eluates corresponding to $\mathrm{tZ}$ and $\mathrm{iP}$ were collected separately. The collected fractions were dried dissolved in $80 \%$ ethanol. After fractionation by HPLC system I the extracts were further fractionated using the same method for HPLC system II. The HPLC column (C-30-S-Select, $5 \mu \mathrm{m}, 4.6 \times 250$ $\mathrm{mm}$, GL Sciences Inc.) was isocratically eluted with a solution of $40 \%$ ethanol $+60 \%$ ultrapure water containing $0.1 \%$ acetic acid. The fractions of $\mathrm{GA}_{1}, \mathrm{GA}_{4}, \mathrm{tZ}$, and iP were injected separately, and eluates corresponding $\mathrm{GA}_{1}$, $\mathrm{GA}_{4}, \mathrm{tZ}$, and iP were collected and dried.

Analysis by LC-MS

LC-MS was performed according to the procedure of Kojima et al. (2020a). We used a LC-MS (LCMS 2010EV, Shimadzu Co., Japan) to identify the hormones: column, Cadenza CD-C18 ( $3 \mu \mathrm{m}, 250 \times 2 \mathrm{~mm}$; Imtakt Co., Kyoto);

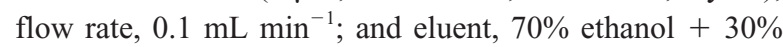
ultrapure water $+0.1 \%$ acetic acid. Selected ion monitoring (SIM) method was selected, and monitoring ions and mode were according to Kojima et al. (2020a). Plant hormone concentrations were calculated from the ratio of the peak areas of natural and labeled ions as an internal standard.

\section{RESULTS}

The weight of melon pulp and whole fruit increased rapidly from 14 to 56 DAF (Fig. 1a). The weight of the placenta part (including seeds) and rind increased at $28 \mathrm{DAF}$, and then remained almost constant, and slightly increased at 56 DAF (Fig. 1a inset). The weight of the peduncle part (including the petiole of about $10 \mathrm{~cm}$ in length) was almost constant after 28 DAF. It is known that cell division of melon pulp terminates at 5 DAF (honeydew melon 'Inodorous Naudin') and 3-4 DAF (new melon 'Makuwa Makino') (Masuda and Hayashi, 1959). Therefore, we assume that the melon fruit in this study terminates its cell division after 14 DAF and the fruit grows due to cell expansion. Soluble solids concentrations in placenta part and pulp showed similar changes (Fig. 1b). It increased slightly at $28 \mathrm{DAF}$, sharply increased at $42 \mathrm{DAF}$, and increased slightly at 56 DAF.

The hormone concentration of whole fruit was calculated by summing the amount of placenta, flesh, and rind hormones per cluster and dividing this value by the FW per fruit. IAA concentration increased at 42 DAF in the placenta part but decreased at 56 DAF (Fig. 2). The flesh increased slightly at 28 DAF but decreased slightly at 42 DAF. Rind showed little change at low concentrations, while the peduncle tended to increase.

The $\mathrm{tZ}$ concentration increased sharply at $42 \mathrm{DAF}$ in the placenta part but rapidly decreased at 56 DAF (Fig. 3a). The rind and peduncle part also increased at 42 DAF and decreased at 56 DAF. There was no considerable change in the flesh. The iP concentration in the placenta part decreased at $28 \mathrm{DAF}$, increased at $42 \mathrm{DAF}$, and rapidly decreased at 56 DAF (Fig. 3b). The flesh did not change strikingly. The rind increased at $28 \mathrm{DAF}$ and decreased thereafter, while the peduncle part showed no remarkable change. In almost all tissues except for $42 \mathrm{DAF}$ in the placenta part, $\mathrm{tZ}$ and $\mathrm{P}$ concentrations were similar, 


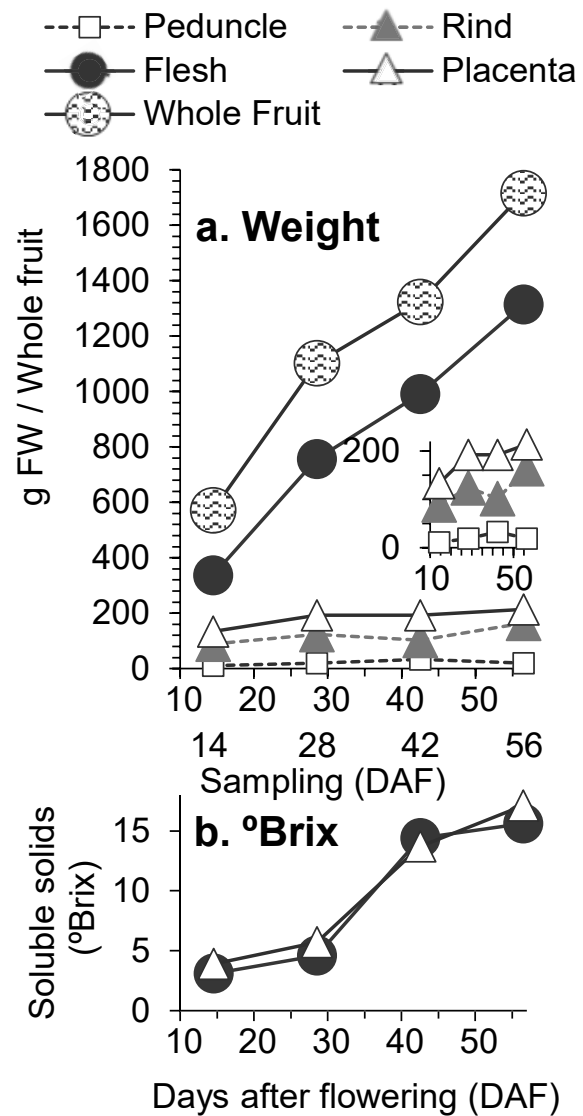

Fig. 1 Changes in weight (a) and soluble solids (b) in the developing melon fruits from 14 to 56 days after flowering (DAF). On each sampling day, 20 fruits are collected and divided into pericarp, flesh, placenta (including seeds), and peduncle (including petioles with a length of about $10 \mathrm{~cm}$ ). Together, they were weighed and then immersed in $80 \%$ ethanol.

thus, in melon; both considered to be the major CKs (Fig. $3 a, b)$.

$\mathrm{GA}_{1}$ levels were generally high in the placenta part, and the flesh tended to increase slowly (Fig. 4a). The rind increased at 42 DAF and dropped sharply at 56 DAF whereas the flesh and peduncle part showed no notable change. $\mathrm{GA}_{4}$ concentration rapidly increased at $28 \mathrm{DAF}$ at the peduncle part and continued to reduce to 56 DAF thereafter (Fig. 4b). The placenta part and rind continued to fall with the progress of fruit growth and the flesh also continued to decline after 28 DAF. Since $\mathrm{GA}_{1}$ and $\mathrm{GA}_{4}$ concentrations were almost the same in almost all tissues except for the peduncle part, both were considered to be the main GA in melon (Fig. 4a, b).

The ABA concentration in the placenta part continued to rise with the progress of fruit growth (Fig. 5). The flesh decreased to 42 DAF and increased sharply at 56 DAF. The rind and peduncle part decreased at $28 \mathrm{DAF}$, and the levels were the same thereafter.

JA concentrations similarly changed in the placenta part and flesh and increased at $28 \mathrm{DAF}$, declined at 42 DAF, and rose at 56 DAF (Fig. 6a). Conversely, the rind showed the opposite change, and the concentration was generally high. The peduncle part tended to decrease.
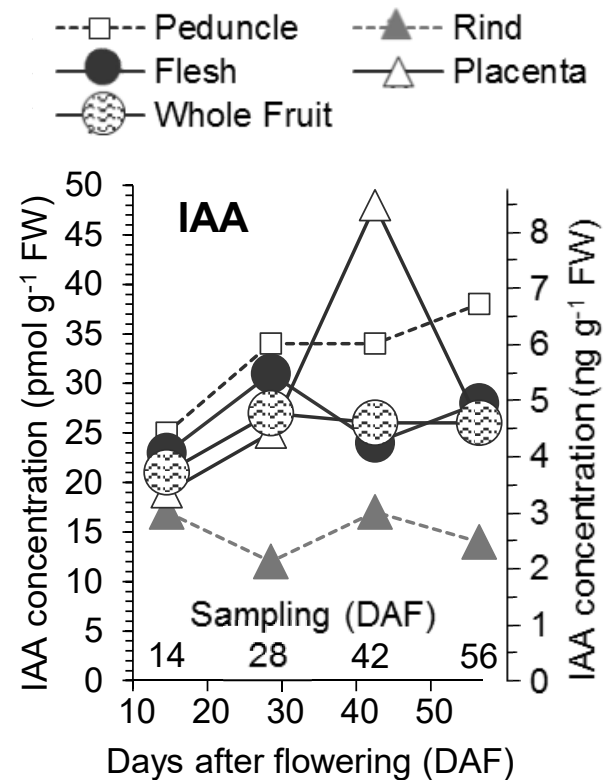

Fig. 2 Changes in endogenous concentration of indole-3-acetic acid (IAA) in the developing melon fruits from 14 to 56 DAF. Twenty fruits were collected at each sampling, and all the fruits were divided into a rind, flesh and placenta with a knife, and each tissue was mixed. An internal standard was added, fractionated by extraction with diethyl ether, purified by high performance liquid chromatography (HPLC), and quantified by liquid chromatography-mass spectrometry (LC-MS).

MeJA concentrations did not change notably in the placenta part, flesh and peduncle part (Fig. 6b). The rind was high at 28 and $42 \mathrm{DAF}$.

\section{DISCUSSION}

Earls melon forms a unique net to the rind (Suzuki and Nonaka, 2004). Melons have cracks between the cells of the rind around $19 \mathrm{DAF}$, and vertical direction cracks can be visually seen. Around 23 DAF, the horizontal direction and fine cracks can be observed virtually. Around 30 DAF, the rind has nets throughout the fruit. The net is a healing cell that is created to restore the cracks, and rises above the fruit surface to form a mesh. It is known that when a plant is stimulated by injury such as a crack, JA and MeJA accumulate and an injury-inducible gene is expressed (Creelman et al., 1992; Farmer et al., 1992; Hildmann et al., 1992). In the rind of this study, the concentrations of JA and MeJA were generally high (Fig. 6). Thus, it is considered that the damage of the crevice during the formation of the unique net of the melon rind raises the concentration of JA and MeJA in the rind and forms the net.

There were few MeJA reports on the endogenous level of fruits, and JA was mainly reported. JA concentration of melon fruit in this study $\left(5^{-10} \mathrm{pmol} \mathrm{g}^{-1} \mathrm{FW}\right)$ and other reported varieties were consistent: apple fruit (12-33 pmol g ${ }^{-1}$ FW) (Fan et al., 1998); grape pulp of 'Thompson seedless' (40-50 pmol g ${ }^{-1} \mathrm{FW}$ ) (Peña-Cortés et al., 2005); grape pulp of 'Campbell Early' (20-90 pmol $\mathrm{g}^{-1} \mathrm{FW}$ ) (Kojima et al., 2020a). Under normal conditions without 

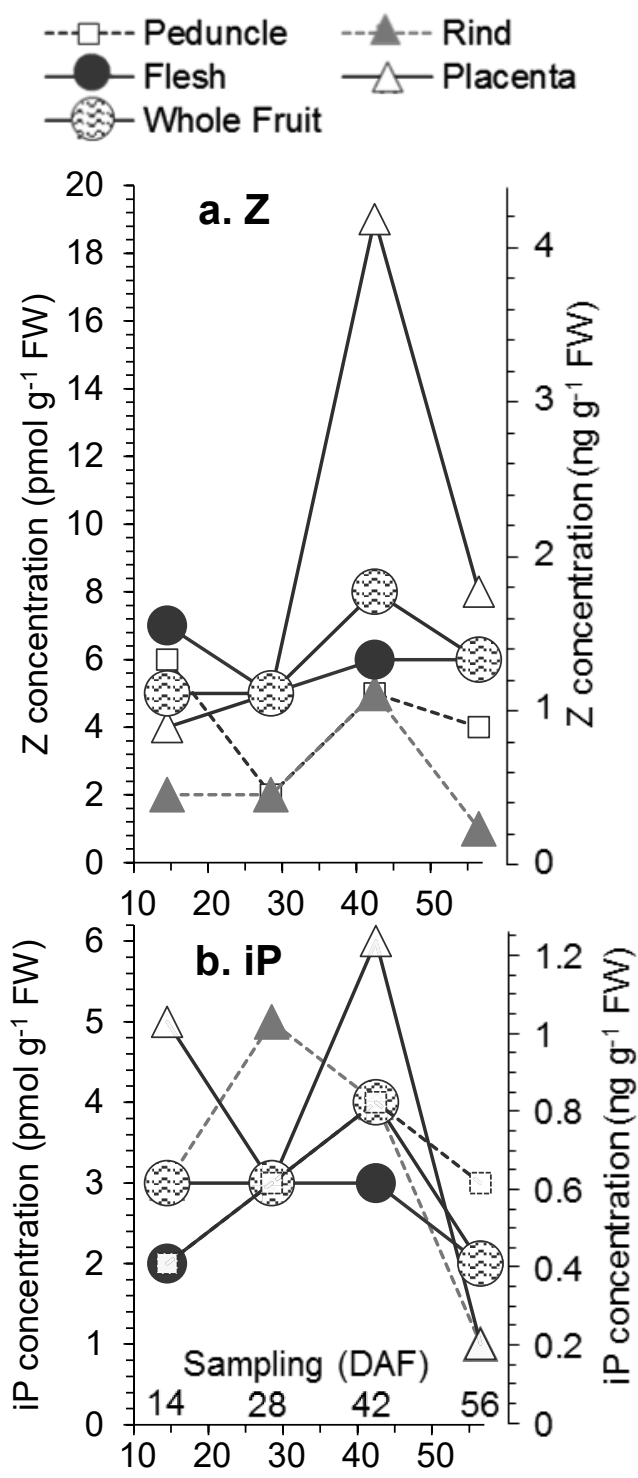

Days after flowering (DAF)

Fig. 3 Changes in endogenous concentration of trans-zeatin (tZ) (a) and isopentenyl adenine (iP) (b) in the developing melon fruits from 14 to $56 \mathrm{DAF}$. Twenty fruits were collected at each sampling, and all the fruits were divided into a rind, flesh and placenta with a knife, and each tissue was mixed. Internal standards were added, fractionated by extraction with butanol, purified by HPLC, and quantified by LC-MS.

injury, fruit JA may be consistent even if the variety differs. However, the watermelon fruit has a slightly higher level (28-112 $\mathrm{pmol} \mathrm{g}^{-1} \mathrm{FW}$ ) (Kojima et al., 2020b), and the analysis of more varieties is needed to verify this possibility.

The placenta part is a soft tissue surrounding the seed. Generally, it softens and liquefies as it grows. Seeds have been reported to have higher IAA concentrations in many fruits than in surrounding tissues (Gillaspy et al., 1993; Kojima et al., 2021). Therefore, it is considered that the IAA concentration in seeds is higher than that in the placenta part.

As physiological effects of ABA, suppression of ger-
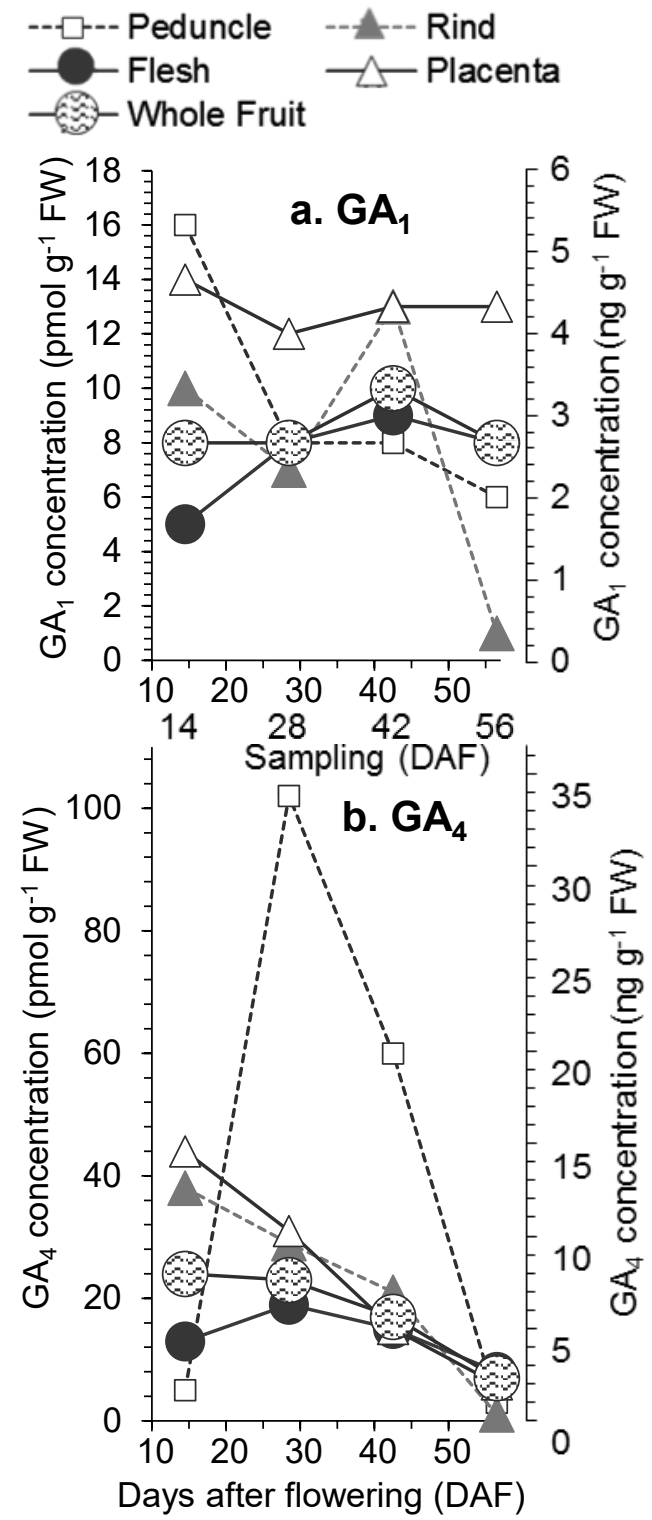

Fig. 4 Changes in endogenous concentration of gibberellins $s_{1}$ $\left(\mathrm{GA}_{1}\right)(\mathrm{a})$ and gibberellins $4\left(\mathrm{GA}_{4}\right)(\mathrm{b})$ in the developing melon fruits from 14 to $56 \mathrm{DAF}$. Each of a rind, flesh and placenta of 20 fruits at each sampling was mixed. Internal standards were added, fractionated by extraction with ethyl acetate, purified by HPLC, and quantified by LC-MS.

mination in fruits, drought tolerance and accumulation of storage proteins in seeds have been reported (Kermode, 1990). Studies have revealed that the reduction of water content during seed ripening in dried fruits such as beans is a factor that suppresses the germination in fruits (Ackerson, 1984). However, the placenta of melons and grapes are filled with fruit juice, and the area around the seeds is always rich in water (Welbaum, 1993). Therefore, studies showed that one of the factors suppressing the germination within the fruit of melon is the effect of drying seeds by the osmotic pressure of the fruit juice, and the second factor that suppresses the germination is ABA (Welbaum et al., 1990). In this study, ABA concentration continued to increase with the progress of fruit growth in the placenta 

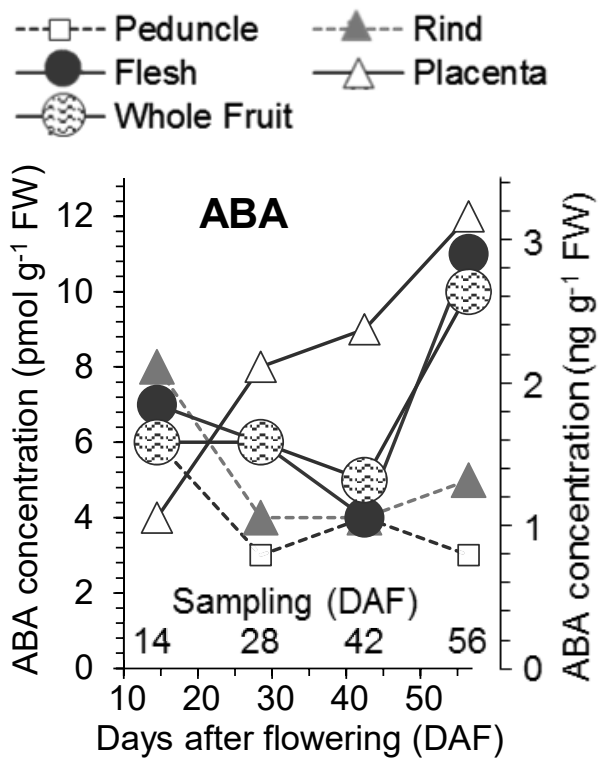

Fig. 5 Changes in endogenous concentration of abscisic acid (ABA) in the developing melon fruits from 14 to 56 DAF. Each of a rind, flesh and placenta of 20 fruits at each sampling was mixed. An internal standard was added, fractionated by extraction with diethyl ether, purified by HPLC, and quantified by LC-MS.

part and rapidly increased at $56 \mathrm{DAF}$ in the pulp (Fig. 5). These results suggest that ABA suppresses germination in melon, although in the report of Welbaum et al. (2000), the ABA concentration determined by ELISA decreased rapidly in the placenta part during 20-60 DAF.

ABA concentration was quantified by ELISA in a test of the influence of nitrate nitrogen application on melon germination in fruits (Ochi and Ito, 2012a). ABA concentrations in the juice tissues (excluding seeds) around the placenta were at $121-489 \mathrm{ng}^{-1} \mathrm{FW}$ at 35 days after pollination (DAP) and $39-60 \mathrm{ng} \mathrm{g}^{-1} \mathrm{FW}$ at 50 DAP. The ABA concentrations in seeds were $34-47$ at 35 DAP and $39-60$ ng $\mathrm{g}^{-1} \mathrm{FW}$ at 50 DAP. Also, studies on the effects of potassium application showed that juice tissue around the placenta was $129-1171$ at $35 \mathrm{DAP}$ and $14-360 \mathrm{ng}^{-1} \mathrm{FW}$ at 50 DAP (Ochi and Ito, 2012b). The ABA concentrations in seeds were $30-68$ at $35 \mathrm{DAP}$ and $8-285 \mathrm{ng} \mathrm{g}^{-1} \mathrm{FW}$ at 50 DAP. ABA quantitation values by ELISA were generally higher than approximately 10 times higher than the data of the placenta part analyzed by mixing juice tissue and seeds around the placenta in this study ( 1 to $3.1 \mathrm{ng} \mathrm{g}^{-1} \mathrm{FW}$ ). Welbaum et al. (2000) determined ABA concentration in melon fruits by ELISA and showed that $50 \mathrm{ng}^{-1} \mathrm{FW}$ or less in the pulp and from 470 to $20 \mathrm{ng}^{-1} \mathrm{FW}$ in the placenta during 20-60 DAF. The results of Welbaum et al. (2000) were generally more than 10 -fold higher than the pulp and placenta (1-3 ng g $\left.{ }^{-1} \mathrm{FW}\right)$ in this study. Although there are differences in the melon varieties and cultivation conditions used, further research is needed on the reliability of the ELISA method that did not use the internal standards.

$\mathrm{GA}_{4}$ concentration was similar in the placenta part, rind and flesh within the fruit (Fig. 4b). However, in the peduncle part outside the fruit, there was a different chan-
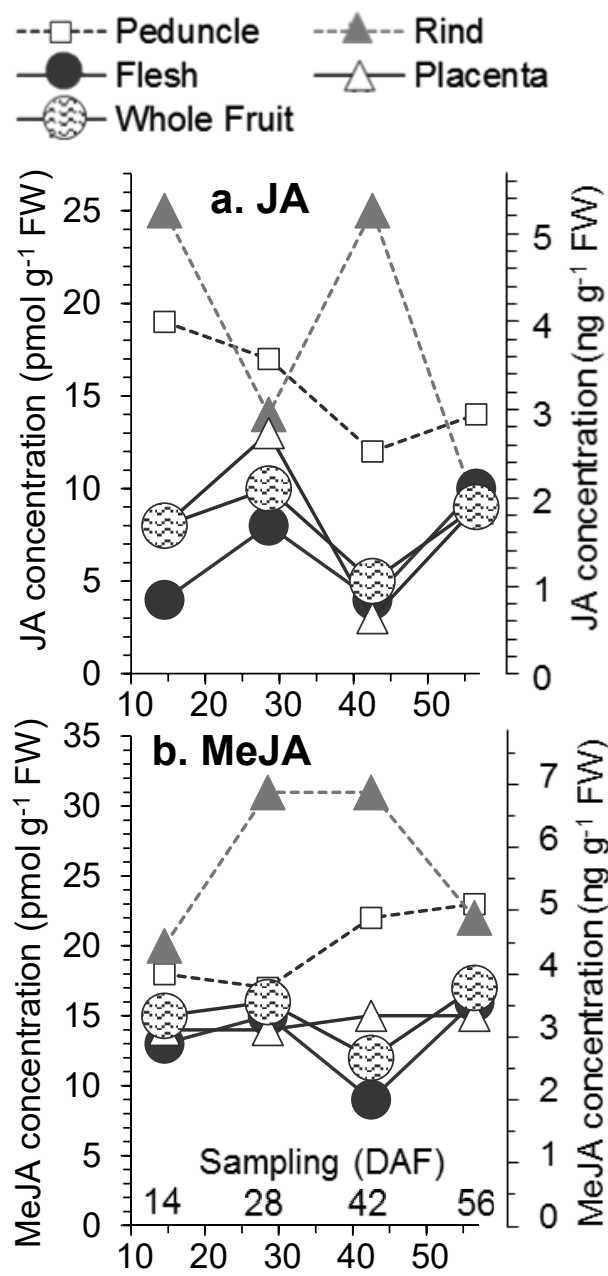

Days after flowering (DAF)

Fig. 6 Changes in endogenous concentration of jasmonic acid (JA) (a) and methyl jasmonate (MeJA) (b) in the developing melon fruits from 14 to 56 DAF. Each of a rind, flesh and placenta of 20 fruits at each sampling was mixed. Internal standards were added, fractionated by extraction with diethyl ether, purified by HPLC, and quantified by LC-MS.

ge, and it rapidly increased at $28 \mathrm{DAF}$ and continued to decrease thereafter. Generally, GA is synthesized in leaves (Wareing and Phillips, 1981) and roots (Davies, 2002) and moves within the vascular bundle. Therefore, it is considered that this rapid increase of the peduncle part is due to the movement from the leaves or roots. In conclusion, our results revealed an endogenous plant hormone profile in melon fruit growth.

In the peduncle and three parts in the fruit, fluctuations that were not synchronized with the eight plant hormones were observed. This indicates that plant hormones are not synthesized to the same extent at each site. If the analysis was performed on the whole fruit without dividing it into parts, specific changes in a specific part were masked. Therefore, it is considered important to analyze plant hormones by the parts to elucidate the physiology of plant hormones. 


\section{K. KOJIMA ET AL.}

\section{ACKNOWLEDGMENTS}

The authors would like to thank Mrs. Kyoko Nagahama for creating the graphs.

\section{REFERENCES}

Ackerson, R. C. 1984. Abscisic acid and precocious germination in soybeans. J. Exp. Bot. 35: 414-421.

Creelman, R. A., Tierney, M. L., Mullet, J. E. 1992. Jasmonic acid/methyl jasmonate accumulate in wounded soybean hypocotyls and modulate wound gene expression. Proc. Natl. Acad. Sci. 89: 4938-4941.

Davies, P. J. 2002. Gibberellins: regulators of plant height. In "Plant Physiology" (ed. by Taiz, L., Zeiger, E.), Ed. 3. Sinauer Associates, Sunderland, p 461-492.

Fan, X., Mattheis, J. P., Fellman, J. K. 1998. A role for jasmonates in climacteric fruit ripening. Planta 204: 444-449.

FAO. 1994. Producion yearbook 1993, Ed. 47. Food and Agriculture Organization of the United nations, Rome.

Farmer, E. E., Johnson, R. R., Ryan, C. A. 1992. Regulation of expression of proteinase inhibitor genes by methyl jasmonate and jasmonic acid. Plant Physiol. 98: 995-1002.

Gillaspy, G., Ben-David, H., Gruissem, W. 1993. Fruits: a developmental perspective. Plant Cell 5: 1439-1451.

Hayata, Y., Li, X. X., Osajima, Y. 2002. Pollination and CPPU treatment increase endogenous IAA and decrease endogenous ABA in muskmelons during early development. J. Am. Soc. Hortic. Sci. 127: 908-911.

Hildmann, T., Ebneth, M., Peña-Cortés, H., Sánchez-Serrano, J. J., Willmitzer, L., Prat, S. 1992. General roles of abscisic and jasmonic acids in gene activation as a result of mechanical wounding. Plant Cell 4: 1157-1170.

Jones, C. M. 1965. Effects of benzyladenine on fruit set in muskmelon. Proc. Am. Soc. Hortic. Sci. 87: 335-340.

Kermode, A. R. 1990. Regulatory mechanisms involved in the transition from seed development to germination. Crit. Rev. Plant Sci. 9: 155-195.

Kojima, K., Ohtake, E., Yu, Z. 2002. Distribution and transport of IAA in tomato plants. Plant Growth Regul. 37: 249-254.

Kojima, K., Tamura, Y., Nakano, M., Han, D., Niimi, Y. 2003. Distribution of indole-acetic acid, gibberellin and cytokinins in apoplast and symplast of parthenocarpic tomato fruits. Plant Growth Regul. 41: 99-104.

Kojima, K., Ikarashi, H., Andou, D., Matsumoto, T. 2020 a. Changes of endogenous plant hormones in growing grape 'Campbell early' fruits. Hortic. J. 89: 509-515.

Kojima, K., Andou, D., Ito, M. 2020b. Plant hormone changes in growing small watermelon fruit. Hortic. J. 90: 202-208.
Kojima, K., Aoki, C., Chino, S. 2021. Profiles of endogenous plant hormones during growth of strawberry fruit on elevated cultivation unit. Environ. Control Biol. 59: 35-39.

Lee, T. H., Kato, T., Kanayama, Y., Ohno, H., Takeno, K., Yamaki, S. 1997. The role of indole-3-acetic acid and acid invertase in the development of melon (Cucumis melo L. cv. Prince) fruit. J. Jpn. Soc. Hortic. Sci. 65: 723-729.

Li, X. X., Hayata, Y., Osajima, Y. 2002. p-CPA increases the endogenous IAA content of parthenocarpic muskmelon fruit. Plant Growth Regul. 37: 99-103.

Masuda, T., Hayashi, K. 1959. Studies on thickening growth of melon fruits. I. On the honey dew and new melon. (In Japanese with English abstract) Bull. Res. Inst. System Hortic. Fac. Agr., Okayama Univ. 14: 71-79.

Ochi, Y., Ito, T. 2012a. Viviparous sprouting of melon seed and endogenous abscisic acid (ABA) levels as affected by nitrate nitrogen fertilization. (In Japanese with English abstract) Hortic. Res. (Jpn.) 11 (Suppl. 1): 37-42.

Ochi, Y., Ito, T. 2012b. Viviparous sprouting of melon seed and endogenous abscisic acid (ABA) levels as affected by potassium fertilization. (In Japanese with English abstract) Hortic. Res. (Jpn.) 11 (Suppl. 1): 43-48.

Peña-Cortés, H., Barrios, P., Dorta, F., Polanco, V., Sánchez, C., Sánchez, E., Ramírez, I. 2005. Involvement of jasmonic acid and derivatives in plant response to pathogen and insects and in fruit ripening. J. Plant Growth Regul. 23: 246-260.

Suzuki, E., Nonaka, T. 2004. Fruit development and net expression. In "Nousangyosonbunkakyoukai. Vegetable Gardening Encyclopedia”, Ed. 2, Vol. 4. Melon. (In Japanese) Noubunkyou, Tokyo, p 86-113.

Wang, J., Horiuchi, S., Ogata, T., Matsui, H. 1993. Relation between the formation of parthenocarpic berries and endogenous plant hormone contents in seedless grape cultivars. (In Japanese with English abstract) J. Jpn. Soc. Hortic. Sci. 62: 914.

Wareing, P. F., Phillips, I. D. J. 1981. Growth \& Differentiation in Plants. Pergamon Press, Oxford.

Welbaum, G. E., Tissaoui, T., Bradford, K. J. 1990. Water relations of seed development and germination in muskmelon (Cucumis melo L.). Plant Physiol. 92: 1029-1037.

Welbaum, G. E. 1993. Water relations of seed development and germination in muskmelon (Cucumis melo L.) VIII. Development of osmotically distended seeds. J. Exp. Bot. 44: 12451252.

Welbaum, G. E., Pavel, E. W., Hill, D. R. 2000. Compartmentation of abscisic acid in developing muskmelon (Cucumis melo L.). In "Seed Biology: Advances and Applications: Proceedings of the Sixth International Workshop on Seeds" (ed. by Black, M., Bradford, K. J., Vázquez-Ramos, J.). CABI, Mérida, p 85-100. 